\title{
CONTINGENCY THEORY: A WORK UNIT APPLICATION
}

\section{H. Richard Eisenbeis and Donna M. Watkins}

\author{
Department of Management \\ Marshall University \\ Huntington, West Virginia
}

Throughout your work experience you have probably seen work units that performed their tasks in radically different ways and with varying degrees of effectiveness. Certainly you have seen situations in which a clearly defined superior/subordinate relationship existed: Rules and procedures were clearly defined, the supervisor gave orders based on these rules, and the role of the employees was simply to carry out the orders. On the other hand, you've probably witnessed work units in which a team approach existed: Rules and procedures were flexible, and the supervisor acted as a coordinator or facilitator of the decisions made by the team of work unit employees.

What is the rationale behind these two different extremes of work unit design? Do such designs simply "happen" by trial and error? Or is it possible for a supervisor to analyze systematically the tasks performed by the work unit and consciously create an overall design that best suits these tasks? The purpose of this article is twofold: first, we will identify some key elements of work units and indicate how the proper relationships among these elements can contribute to a work unit's effectiveness; second, we will discuss some strategies for creating the proper relationships within a work unit.

The basis for identifying and structuring these work unit elements into a viable framework is known as contingency theory or a situational approach to management (5). According to this managerial approach, all work unit elements in a particular work situation exist in a specific state or condition. If we were to display the state or condition of these elements graphically, we could see that each of them is positioned somewhere along a scale of one to five. The positions of some elements can be changed or controlled, while the positions of others cannot. For increased effectiveness to occur in this work situation, the positions of the controllable elements should be altered so that they align or fit with the positions of the uncontrollable elements. Graphically, we would want all elements aligning at some particular point on the scale (Figure 1). In other words, the desired positions of some elements are contingent upon the positions of one or more elements. 

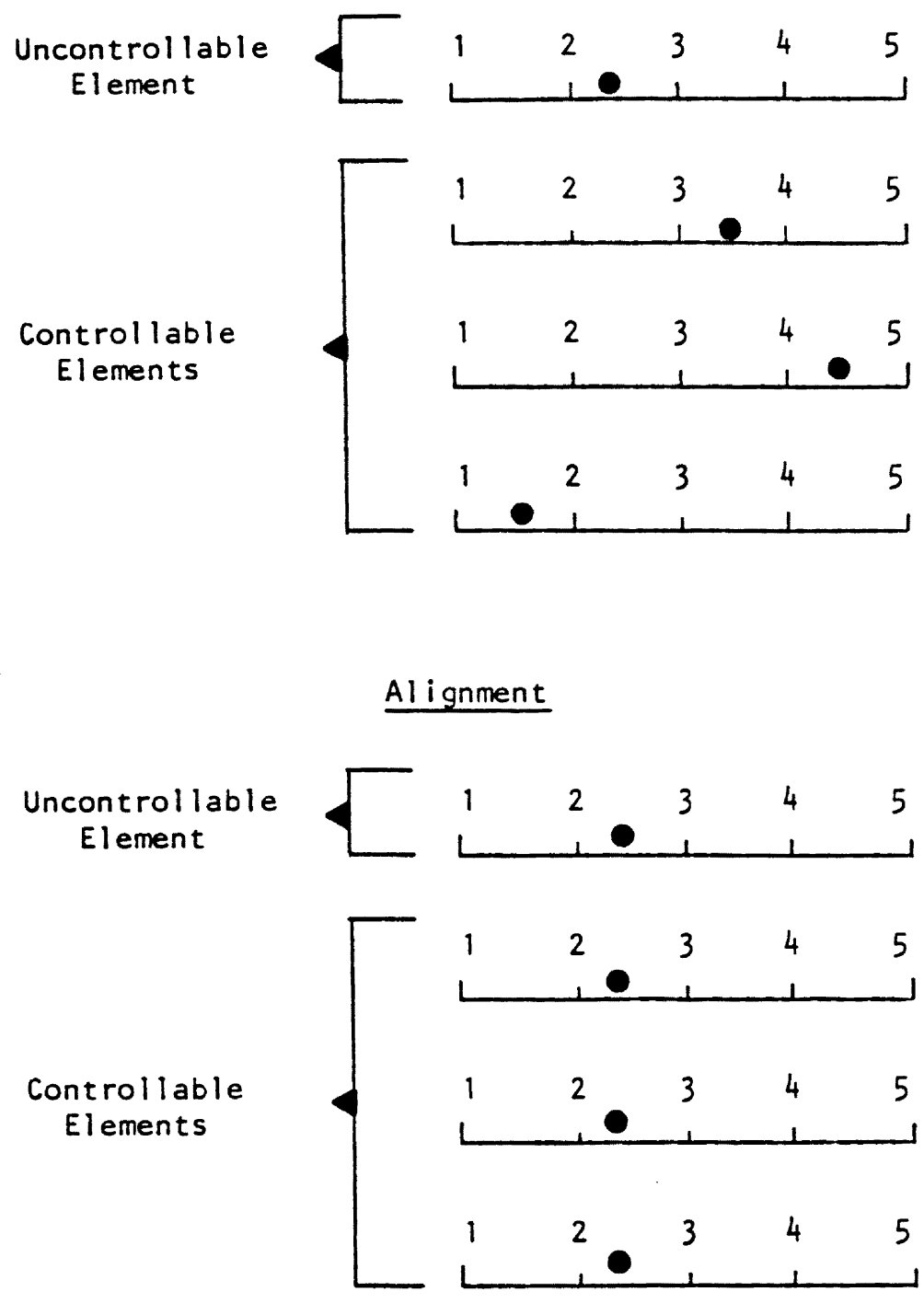

Figure 1. Examples showing misalignment and alignment of work unit elements.

\section{Work Unit Elements and Their Relationships}

The key elements of the work unit are the technology used or tasks performed, the structure created by established rules and procedures, the leadership style of the supervisor, and the attitudes of the employees toward their supervisor and work environment (8).

Technology. The technology used or tasks performed by a work unit include all equipment, skills, and knowledge necessary to change raw materials into finished products or services. Technologies range from routine or well developed to nonroutine or highly problematic. In routine 
technologies, tasks have been reduced to their simplist form and are highly repetitive; in nonroutine technologies, tasks are difficult and highly diversified, requiring high levels of skill and knowledge. An assembly line is an example of a routine technology; a research medical laboratory, an example of a nonroutine technology. Certainly, the technology for manufacturing the average automobile is more routine and developed than is the technology for curing cancer.

Obviously, several work unit technologies generally exist within one firm. This combination of work unit technologies is established to satisfy the overall goals and objectives of the firm. For example, a study of the domestic copper industry (3) shows that the identifiable work unit technologies extend across the entire routine/nonroutine scale: 1) production (most routine), 2) general business functions, 3) engineering, 4) sales and marketing, and 5) research and development (least routine).

Structure. The work unit's structure includes all policies, procedures, standards, job descriptions, and hierarchical levels. Differences in work unit structures range from highly defined to loosely defined. Highly defined structures are characterized by distinct functional or job specialties, precise definitions of duties and responsibilities, and a well-defined command hierarchy; loosely defined structures are characterized by more flexibility, less rigorously specified jobs, and participative decision making (1).

The individual work unit technology or tasks performed should determine how the work unit is structured. As work unit technologies vary from routine to nonroutine, work unit structures should vary from highly defined to loosely defined (11).

For the sake of comparison, let us consider an assembly line operation and a research project. To be efficient and competitive, an assembly line operation needs clear cut lines of authority and a host of formal organizational policies, procedures, standards, and job descriptions to ensure tasks are coordinated and completed within a specified time frame. In assembly line situations, widespread job freedom and unrestricted interaction among workers have the potential for introducing high levels of inefficiency into the work environment. Conversely, research scientists could not exhibit the high levels of innovation or creativity required if their activities were as closely defined and regimented as those of the assembly line workers. In research and development situations, structures should be loosely defined to ensure that proper interaction occurs among unit members, thus enhancing the creative process.

Leadership style. The leadership style of a work unit supervisor is the manner in which the supervisor guides employees toward goal attainment in a given situation. Differences in leadership styles range from directive to democratic. Directive leaders generally define and structure precisely the roles of their subordinates toward goal attainment and pay little attention to their subordinates' ideas and feelings; democratic leaders generally allow 
subordinates to participate in the definition and structure of their roles and show more respect for their subordinates' ideas and feelings (6).

The work unit structure (derived from work unit technology) should determine the appropriate leadership style. Therefore, leadership styles should vary along the following scale: the more routine the technology and the more highly defined the structure, the more directive the leadership style should be; the more nonroutine the technology and the more loosely defined the structure, the more democratic the leadership style should be.

First, let us consider situations where technologies are routine and structures are highly defined. Because in these situations the work process is rigidly defined and employees generally do not possess the knowledge or skill to modify or improve the system, they can provide little useful creative input. A supervisor and his superiors alone should be responsible for making decisions regarding individual tasks or systems design. In addition, a directive supervisor should make sure that rules and procedures are followed closely, that minimum standards are met, and that employees are treated equitably and fairly.

Another possibility encompasses middle-of-the-road situations. As tasks become less routine and demand more relaxed structures, the leadership style needs to become more consultive and participative because employee input becomes progressively more important to the success of the task being performed.

Finally, let us examine the technological and structural situations where tasks are nonroutine and structures are loosely defined. In these situations, effective decision making requires sustained input from all work unit members. The primary roles of a work unit leader should be to procure essential resources and information to enable the group to function at peak levels and to protect the group from disruptive outside interference. Apart from these functions, there may be little to differentiate a democratic work unit leader from the rest of the group members. The leader will often possess only the same general level of expertise as other unit members and perhaps less in some specific areas.

Employee attitudes. Employee attitudes include attitudes toward acceptance of authority, ambiguity, job complexity, and individualism (desire to work independently). These attitudes appear to be related to competence, productivity, and satisfaction on the job (8). Differences in these attitudes denote a full range of personality traits between the extremes of conformity and nonconformity. Conformists are employees who welcome authority, are generally intolerant of ambiguity, are intolerant of complex jobs, and prefer to work in conjunction with others. In contrast, nonconformists are employees who are less tolerant of direct authority, are challenged by ambiguous, complex situations, and prefer to work alone.

Most of us, consciously or unconsciously, have encountered employees with both conformist and nonconformist attitudes. Conformists willingly 
accept being told what to do and how to do it. They generally experience anxiety and stress if they do not have a fairly clear idea what jobs they will be doing tomorrow, next month, or even a year from now. If conformists encounter ambiguous situations, they will actively seek guidance to resolve the ambiguities. In contrast, nonconformists do not welcome being told what to do and how to do it; they may even show open resentment to minimum supervision. Knowing precisely what is expected of them for days or months on end causes nonconformists stress and anxiety; they become bored rather quickly if they are not confronted with job situations that demand them to choose among conflicting or ambiguous alternatives.

In addition to acceptance of authority and tolerance of ambiguity, conformists and nonconformists also differ in their attitudes toward problem solving or job complexity. While many employees exhibit the desire to solve work-related problems and find more efficient ways of completing tasks, just as many employees do not exhibit this desire. Conformists would fall into the latter category; they find the environment of complex jobs disastrous. On the other hand, nonconformists are very comfortable in a job where solving complex problems through new and innovative approaches are the norm.

The final important difference between conformists and nonconformists is the relative desire for individualism on the job. Some employees find it difficult to perform if they do not have the opportunity to interact frequently with other individuals. If the supervisor assigns conformists a task that requires isolation for a long period of time, they take advantage of every opportunity to be with others. Often conformists' offices are vacant; they socialize more than usual with other employees or even interact more than is necessary with the supervisor. Conformists cannot tolerate working for long periods of time removed from eye contact or without the opportunity to interact with other individuals. This is not so with nonconformists. Employees with a strong sense of independence and individualism behave very differently. Nonconformists are those individuals who arrive early at work, go directly to their offices and shut the door, and begin working. They seldom take a coffee break, frequently work through their lunch period, and may continue working after closing time. The supervisor may even get the impression that he is intruding upon sacred ground when he enters a nonconformist's work domain.

Work unit technology, structure, and leadership style should dictate the type of employees that are selected for the work unit. Employees with conformist attitudes are most productive and satisfied with their jobs when work unit technologies are routine, structures are loosely defined, and leadership styles are directive; employees with nonconformist attitudes are most productive and satisfied with their jobs when work unit technologies are nonroutine, structures are loosely defined, and leadership styles are democratic (8). A viewpoint that conformists are undesirable and noncon- 
formists are desirable (or vice versa) has no place in the contingency approach. There are no good guys or bad guys. Either conformist or nonconformist attitudes (or possibly some point in between) are essential to work unit effectiveness if the attitudes of the employee align with the demands of the tasks being performed. The attitudes of assembly line workers should be different from those of office personnel, which in turn should be different from those of engineers, etc.

Summary. As shown in the foregoing discussion, each work unit element is tied to another or several other elements. If we look at the extremes of each work unit element scale, we can see a definite matching or alignment process taking place. Figure 2 shows the expected alignment of the elements according to different work units. While matching the extremes of each element on a "scale basis" helps us understand the alignment process, we certainly do not mean to imply that all similar work units (all production or all engineering, etc.) in all firms should have identical work unit alignments. Such a narrow interpretation of alignment concepts would overlook the basic key of contingency theory-the analysis of elements within a particular work situation. Work unit technologies vary not only in amount of routineness between types of work units but also in degree of routineness within types of work units. Therefore, any work unit in any organization should have a structure, a leadership style, and employee attitudes that align with the demands of the tasks being performed in that particular work unit.

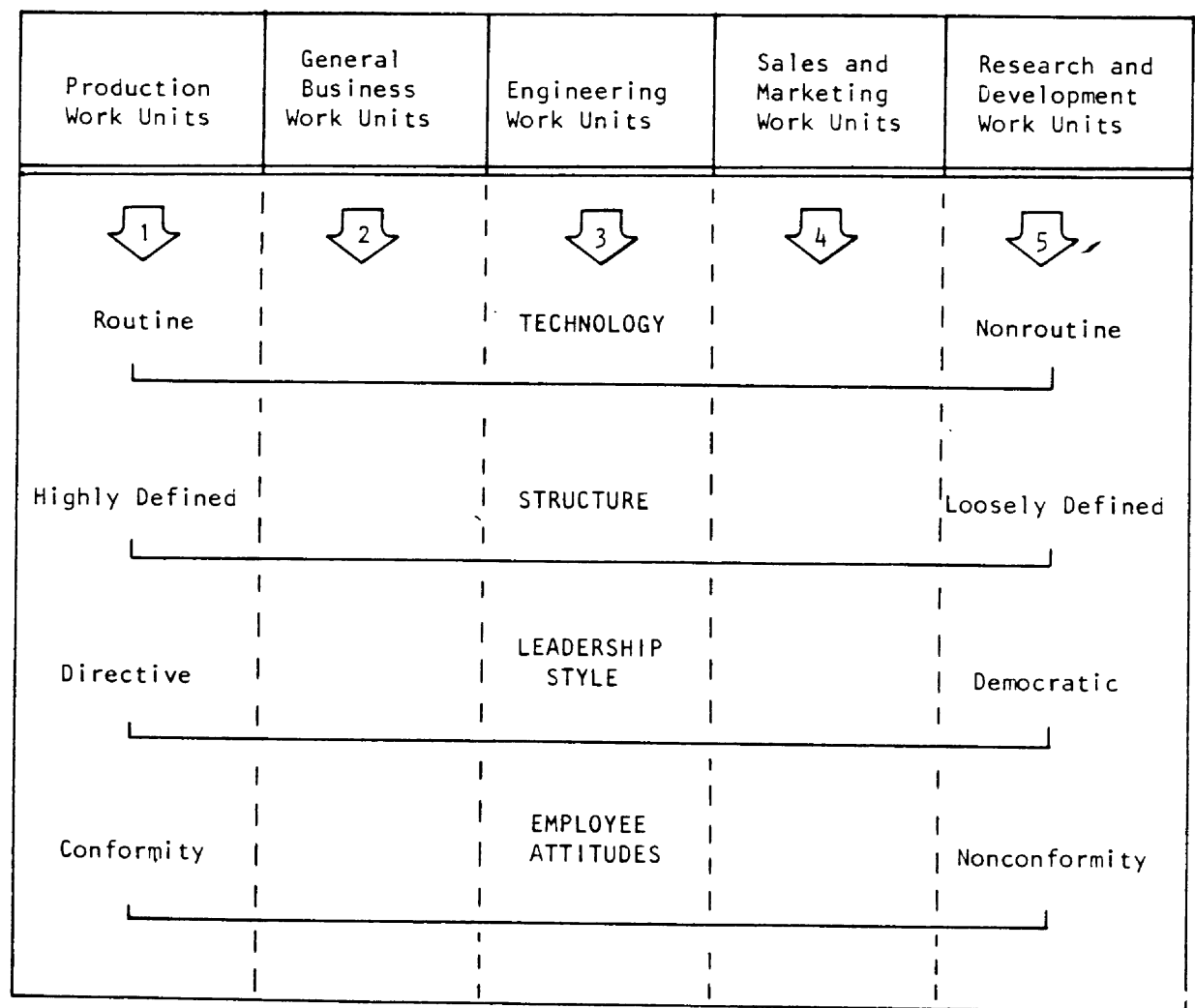

Figure 2. Work unit alignments leading to higher degrees of effectiveness. 


\section{Strategies for the Work Unit Alignment Process}

The key to applying these contingency concepts is identifying the proper fit or alignment of the elements in a given work unit situation. It is the role of the work unit supervisor and his superior to assess the state of these elements and attempt to bring them into alignment if necessary. Given the proper authority, the supervisor can control or alter the state of most of these elements.

\section{Technology and Structure}

Top management personnel select those work unit technologies for incorporation in the firm that they believe will best serve the organization's purpose. Work unit supervisors have little to say in the selection process of the technology itself. But as previously indicated, work unit structure should be determined by the confines of the tasks being performed. It is the role of the supervisor and his superior to select the work unit structure that best matches the designated technology.

If the technology is routine or well developed, the supervisor should establish job duties, rules, procedures, and reporting activities that match the specificity of the technology. A clearly defined chain of command should exist. If the tasks are less routine and more human thought processes are required to accomplish the tasks, then the rigidness of the structure should decrease, creating an environment for informal group interaction and participative decision making.

\section{Leadership Style}

Through his leadership approach, the supervisor must balance the technological and structural demands of the work unit with the personalities of the employees. But a supervisor should show sincere concern for both the interests of the organization and the individual only as circumstances permit: There are limits as to how much attention can be afforded to subordinates' ideas and feelings in routine tasks and how much leader-initiated role structure should be imposed upon nonroutine tasks. The proper balance is highly situational and often times dynamic. The supervisor must continually monitor work unit elements and adjust his leadership style accordingly to keep the unit functioning effectively.

A word of caution is warranted here. Assessment of the supervisor's leadership style (directive, democratic, or somewhere in between) and the flexibility of that style is necessary. If the supervisor's style is inflexible and does not match the technology and structure of the work unit, the supervisor may well suffer extreme stress and anxiety over his role, especially when things are not going well. Perhaps that supervisor should ask to be moved to a work unit in which his leadership style can be more effectively 
used. Such a change should result in more personal satisfaction and reduced tension for the supervisor and increased effectiveness for the work unit. Even in a situation where the supervisor's style matches the work unit's technology and structure, an additional problem can arise if that supervisor's style is inflexible and the supervisory position is part of a career path. A career path position requires consideration of his potential to adapt to all future positions.

\section{Employee Attitudes}

The personnel dimension is perhaps the most important element the unit supervisor can control if given the authority. Ideally, work unit personnel should be selected according to how closely their work attitudes align with the technological and structural demands of the work unit. An organization cannot afford the great amount of time it takes to change individual behavior patterns to fit a particular work environment. Therefore, a unit supervisor should request personnel screening through attitude tests before employees are assigned to the work unit to ensure that individual attitudes toward the job are compatible with the demands of the job itself.

The supervisor should be careful not to confuse intelligence level and personal attitudes. Intelligence level is an individual's capacity to learn and to modify behavior; it is inherited. In contrast, personal attitudes begin forming at birth and continue forming throughout an individual's lifetime. These attitudes are culturally conditioned and reflect unique adjustments that an individual makes to his environment. Certainly, some minimum level of intelligence is essential for performing all job activities; yet without the proper attitudes regarding authority, ambiguity, complexity, and individualism, an employee cannot experience the lasting feeling of competence necessary to perform at peak levels.

\section{The Successful Use of the Contingency Approach}

An extensive study of three different industries (8) showed that when alignment occurred among work unit elements, employees did indeed experience a high sense of competence. In turn, this high sense of competence was directly linked to high levels of output as well as to high job satisfaction and low absenteeism and turnover. For a contingency approach to achieve its intended returns of increased employee competence and output, a work unit supervisor and his superior must fully understand the alignment process and possess the knowledge and skills to bring the work unit into balance once they become aware of any misalignment. 


\section{Measuring Alignment}

Numerous test instruments have been devised that measure various dimensions of work unit technology, work unit structure, individual leadership styles, and selected attitudes of personnel. As one would expect, some test instruments are more easily administered and scored than others. In this light, the following test instruments are recommended. Use of these instruments are, of course, subject to any copyright or permission regulations of the publishers.

Technology instrument. The technology instrument devised by Van de Ven and Delbecq (13) measures task difficulty and task variability (degree of routineness). Respondents are asked to answer 14 questions, with each question having ten possible responses (a ten-interval scale). This instrument is described in the June 1974 issue of Administrative Science Quarterly (Cornell University, Ithaca, New York). Sample questions are as follows:

\section{Task Difficulty}

1. To what extent is there a clearly defined body of knowledge or subject matter that can guide you in doing your work?

2. To what extent is there an understandable sequence of steps that can be followed in doing your work?

\section{Task Variability}

3. How much variety in cases, claims, clients, or things do you generally encounter in your working day?

4. To what extent would you say your work is routine?

Structure instrument. The structure questionnaire developed by Lorsch and Morse (8) measures patterns of formal relationships and duties; formal rules, work procedures, and control systems; and the time constraints of formal work practices. Respondents are requested to answer 21 questions along a seven-interval scale. This instrument is described in Organizations and Their Members: A Contingency Approach (Harper \& Row, Publishers, Inc., New York). Examples of questions are as follows:

1. Our management isn't so concerned about formal organization and authority, but concentrates instead on getting the right people together to do the job.

2. There are a lot of rules, policies, procedures, and standard practices one has to know to get along in this unit.

3. It is possible for employees in this unit to commit resources for periods of time ranging from: (scale answers range from "none" to "five years"'). 
Leadership style instruments: The Leadership Opinion Questionnaire (LOQ) and the Supervisory Behavior Description Questionnaire (SBDQ) are appropriate instruments to measure leadership style. These instruments measure the leadership dimensions of consideration and initiating structure. Supervisors are requested to answer 40 questions (LOQ) describing their own leadership style and subordinates 48 questions (SBDQ) describing the leadership style of their supervisor along a series of five-interval scales. The LOQ is available from Science Research Associates, Inc. (Chicago, Illinois) and the SBDQ from the Management Research Institute (Washington, D.C.). Samples questions are as follows:

\section{Consideration}

1. Give in to your subordinates in discussion with them. (LOQ)

2. He helps people in the work unit with their personal problems. (SBDQ)

\section{Initiating Structure}

3. Rule with an iron hand. (LOQ)

4. He insists that people under him follow standard ways of doing things in every detail. (SBDQ)

Consideration reflects the extent to which an individual is likely to have job relationships with his subordinates as characterized by mutual trust, respect for their ideas, and concern for their feelings. Initiating structure reflects the extent to which an individual is likely to define and structure his own role and those of his subordinates toward goal attainment (4).

Personnel attitudes instrument. The personnel attitudes questionnaire developed by Lorsch and Morse (8) measures employee attitudes toward acceptance of authority, tolerance for ambiguity, and desire to work alone or with others. Respondents are requested to answer 21 questions along a seven-interval scale. This questionnaire is described in Organizations and Their Members: A Contingency Approach (Harper \& Row, Publishers, Inc., New York). Sample questions are as follows:

\section{Acceptance of Authority}

1. Even children know they must decide their actions; their fathers and mothers do not know best.

\section{Tolerance for Ambiguity}

2. Doing the same thing in the same place for long periods of time makes for a happy life. 


\section{Desire to Work Alone}

3. A person usually can get the job done faster and better by working alone than with a group.

Administration and scoring of instruments. A questionnaire packet containing each of the test instruments is assembled and administered to all work unit personnel. The packets for supervisors and subordinates are identical except for the leadership questionnaires: the supervisor packet includes the Leadership Opinion Questionnaire, while the subordinate packet includes the Supervisory Behavior Description Questionnaire.

The test instrument for each work unit element is scored by dividing the total number of points accumulated by the total number of points possible for that test instrument. To avoid giving too much weight to nonsupervisory positions and not enough weight to the unit supervisor, the score for the subordinates should be averaged with the unit supervisor's score, as illustrated by Van de Ven and Delbecq (13).

For example, consider a work unit with a supervisor and 20 subordinates. The total points possible for the subordinate technology measure (14 questions, ten-interval scale, 20 respondents) is $14 \times 10 \times 20$ or 2800 . If the total number of points scored for this instrument unit wide is 1820 , the score would be $.650(1820 \div 2800)$. If the supervisor's point total for technology is 77 , then the supervisor's score is $.550[77 \div(14 \times 10 \times 1)]$. The unit score then becomes $.600[(.650+.550) \div 2]$. These steps are repeated for each of the measuring instruments and the scores plotted along separate scales assigned numerical values ranging from 0 to 1.000 .

An example of plots of test instrument data for a work unit showing fairly close alignment of work unit elements with work unit technology is given in Figure 3. In this example, technology is positioned slightly toward the nonroutine end of the scale as are work unit structure, leadership style, and personnel attitudes. The recommended alignment configuration of elements is present.

When one or more of the elements measured shows a radically different scale position from technology and the overall performance of the unit is unsatisfactory, efforts should be made to bring the element or elements back into as close an alignment with work unit technology as is practical or possible.

Measuring alignment of work unit elements assumes added importance in organizations where multiple work units perform the same or very similar tasks but at varying levels of effectiveness. In these situations, the alignment of elements in both the more-effective and less-effective work units should be measured and compared. If marked differences are observed in the alignment of elements between the more-effective and less-effective units, a serious attempt should be made to realign elements in the less-effective 
work units to resemble the alignment configurations noted in the moreeffective work units. The key here is effectiveness. No changes are necessary when alignments vary from work unit to work unit as long as each unit is operating effectively.

\section{Initiating Changes}

Possessing the knowledge and skills of contingency concepts is useless unless the supervisor has the authority to bring about changes in alignment when necessary. Obviously, the successful use of the contingency approach is more likely when a strong organizational commitment exists rather than simply a work unit commitment. Ideally, top management should promote
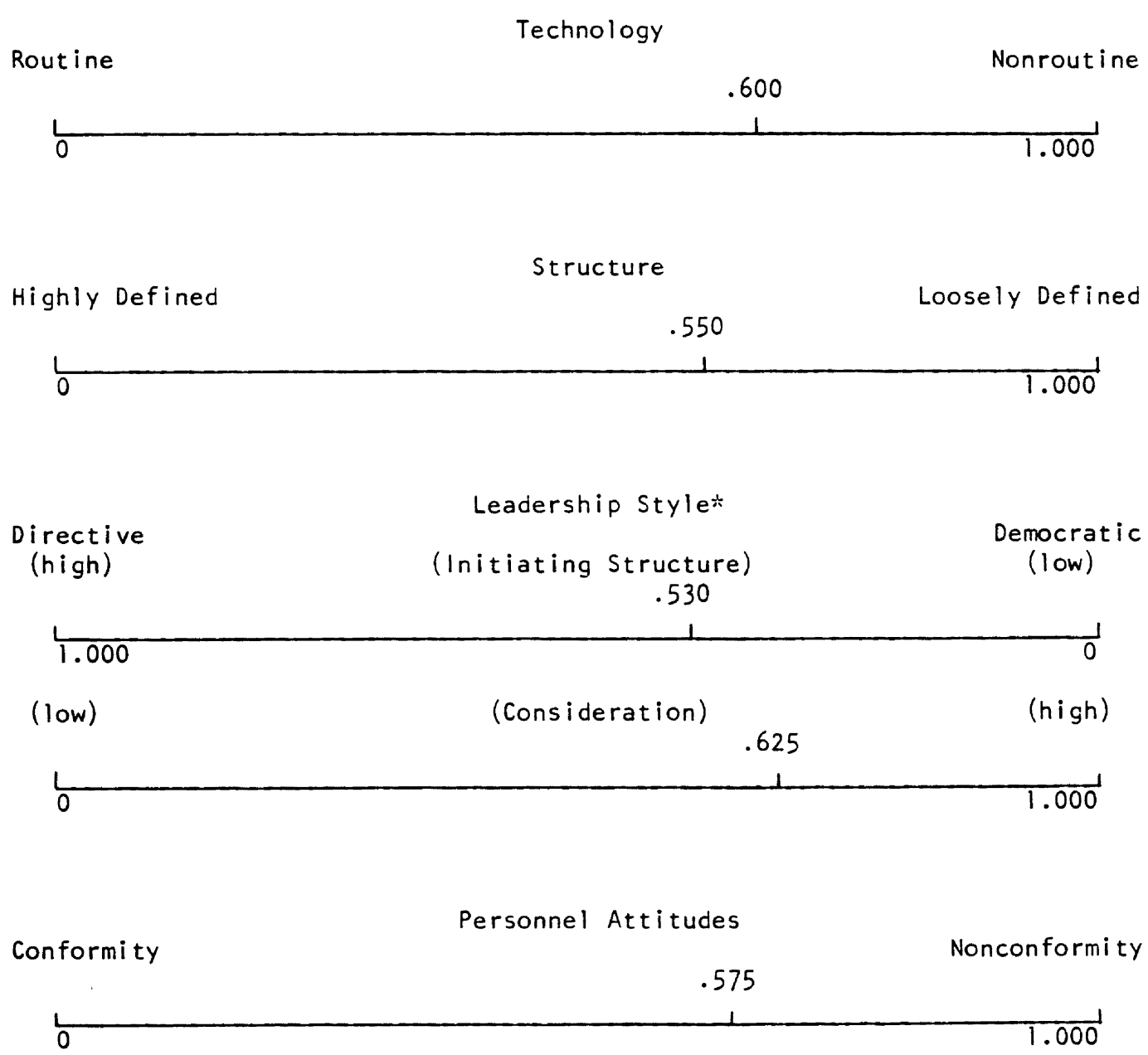

Figure 3. Hypothetical alignment of test instrument measures for work unit technology, structure, leadership style, and attitudes of personnel.

"Leaders showing high consideration toward subordinates exercise more democratic leadership styles while leaders showing high initiating structure exercise more directive leadership approaches. 
work unit alignment by delegating the appropriate authority to the work unit supervisors and by establishing training programs to educate all management employees regarding contingency concepts.

Even when a strong organizational commitment does not exist, a unit supervisor may already have sufficient power to institute alignment changes and increase effectiveness. Whether or not the supervisor has this power depends upon a combination of organization size and top management philosophy. In a small organization in which the proprietor or top management group can closely monitor the work units, the unit supervisor's power to make changes depends upon the amount of freedom given the supervisor to do the job as he sees fit. In a large centralized organization, a supervisor may be hampered by bureaucratic rules and procedures that make adjustments in work unit design difficult. In a large decentralized organization, the supervisor is less encumbered by bureaucratic rules that would limit his freedom to control his work unit in the manner he desires; a unit supervisor in this type of organization may possess the power to make work unit adjustments regardless of top management's philosophy.

Yet, even when the unit supervisor does possess sufficient power and no organizational commitment exists, two unintended consequences can occur. First, a work unit with a design different from the designs of other work units often cannot maintain its unique design and remain effective once the person in power is promoted, seeks employment elsewhere, etc. This usually occurs because the supervisor has not adequately explained to his superiors why the unit experienced higher levels of output. (Perhaps he did not even realize why.) Second, other work unit supervisors may attempt to imitate the management techniques of the more effective unit, never realizing that their units require completely different alignments of elements to increase effectiveness.

When work units with properly aligned elements already exist, whether by design of the unit supervisor or by chance, decision makers should draw upon the experiences of those work units and strive for an organizational commitment. Explaining why some work units are more effective than others can establish a base for the continued use of the contingency approach in those work units and for the possible extension of effective alignments throughout the firm.

\section{REFERENCES}

1. Burns, T. and G.M. Stalker. The Management of Innovation. London: Tavistock, 1961.

2. Child, John. "Organizational Structure, Environment and Performance: The Role of Strategic Choice." Sociology, 6:1-22, 1972.

3. Eisenbeis, H. Richard. Work Unit Technology, Structure, Leadership Style, and Personnel: A Contingency Framework. Unpublished doctoral dissertation, University of Arizona, Tucson, 1980. 
4. Fleishman, E.A. "The Description of Supervisory Behavior." Journal of Applied Psychology, 36:1-6, 1953.

5. Flippo, E.B. and G.M. Munsinger. Management. Boston: Allyn-Bacon, 1982.

6. Kerr, Steven, C.A. Schrieshelm, C.J. Murphy, and Ralph M. Stogdill. "Toward a Contingency Theory of Leadership Based Upon Consideration and Initiating Structure Literature." Organizational Behavior and Human Performance, 12:62-82, 1974.

7. Lawrence, P. and J.W. Lorsch. Organization and Environment. Boston: Harvard Business School, Division of Research, 1967.

8. Lorsch, J.W. and John J. Morse. Organizations and Their Members: A Contingency Approach. New York: Harper and Row, 1974.

9. Magnusen, Karl O. (ed.) Organizational Design, Development, and Behavior: A Situational View. Springfield, Illinois: Scott Foresman and Company, 1977.

10. Miles, R.E. and C.C. Snow. Organizational Strategy, Structure, and Process. New York: McGraw-Hill, 1978.

11. Perrow, Charles. "A Framework for the Comparative Analysis of Organizations." American Sociological Review, 32:194-208, 1967.

12. Thompson, James. Organizations in Action. New York: McGraw-Hill, 1967.

13. Van de Ven, A.H. and A.L. Delbecq. "A Task Contingent Model of Work Unit Structure." Administrative Science Quarterly, 19:183-197, 1974.

14. Withey, M., R.L. Daft, and W.H. Cooper. "Measures of Perrow's Work Unit Technology: An Empirical Assessment and a New Scale." Academy of Management Journal, 26:45-63, 1983.

15. Woodward, Joan. Industrial Organization, Theory, and Practice. London: Oxford University Press, 1965. 